\title{
Alternative SEM techniques for observing pyritised fossil material
}

\author{
Imogen Poole *, Geoffrey E. Lloyd \\ School of Earth Sciences, University of Leeds, Leeds LS2 9JT, UK
}

Received 7 December 1999; received in revised form 22 May 2000; accepted for publication 26 May 2000

\begin{abstract}
Two scanning electron microscopy (SEM) electron-specimen interactions that provide images based on sample crystal structure, electron channelling and electron backscattered diffraction, are described. The SEM operating conditions and sample preparation are presented, followed by an example application of these techniques to the study of pyritised plant material. The two approaches provide an opportunity to examine simultaneously, at higher magnifications normally available optically, detailed specimen anatomy and preservation state. Our investigation suggests that whereas both techniques have their advantages, the electron channelling approach is generally more readily available to most SEM users. However, electron backscattered diffraction does afford the opportunity of automated examination and characterisation of pyritised fossil material. (C) 2000 Elsevier Science B.V. All rights reserved.
\end{abstract}

Keywords: crystal orientation; fossil; plant; pyrite; SEM

\section{Introduction}

Organic material is susceptible to decay but with appropriate conditions can become fossilised. Mineralisation to pyrite, i.e. pyritisation, is known to preserve animal remains (e.g. Stürmer and Bergström, 1973; Hudson, 1982; Briggs et al., 1991, 1996) and is one of the most important modes of plant preservation. However, the factors that determine which tissues and in what settings pyritisation occurs are poorly understood. Numerous studies have been undertaken, both in the laboratory and in modern, mainly marine sediments, in order to understand the process(es) of sedimentary pyrite formation and the chemistry of the reactions

* Corresponding author. Present address: Organic Group, Faculty of Earth Sciences, Utrecht University, P.O. Box 80021, 3508 TA Utrecht, The Netherlands. involved in pyritisation (e.g. Barghoorn and Nichols, 1961; Rixon, 1976; Berner, 1984, 1985; Kenrick and Edwards, 1988, and references cited therein; Drobner et al., 1990; Canfield and Raiswell, 1991; Raiswell et al., 1993; Briggs et al., 1996; Raiswell, 1997; Rickard, 1997; Rickard and Luther, 1997). Within the plant realm the actual process of pyritisation has been largely neglected except for the work of Kenrick and Edwards (1988). To help the understanding of pyritisation in plant remains, these authors combined scanning electron microscopy (SEM) and mineralogical techniques.

To date, most research on the anatomy of pyritised plant material has centred on reflected light microscopy of polished surfaces and SEM of fractured surfaces (Wilkinson, 1981, 1984, 1988; Poole and Wilkinson, 1992, 1999; Poole, 1993, 1996; Kenrick 1999). Both techniques have their advantages and disadvantages. For example, 
PLATE I
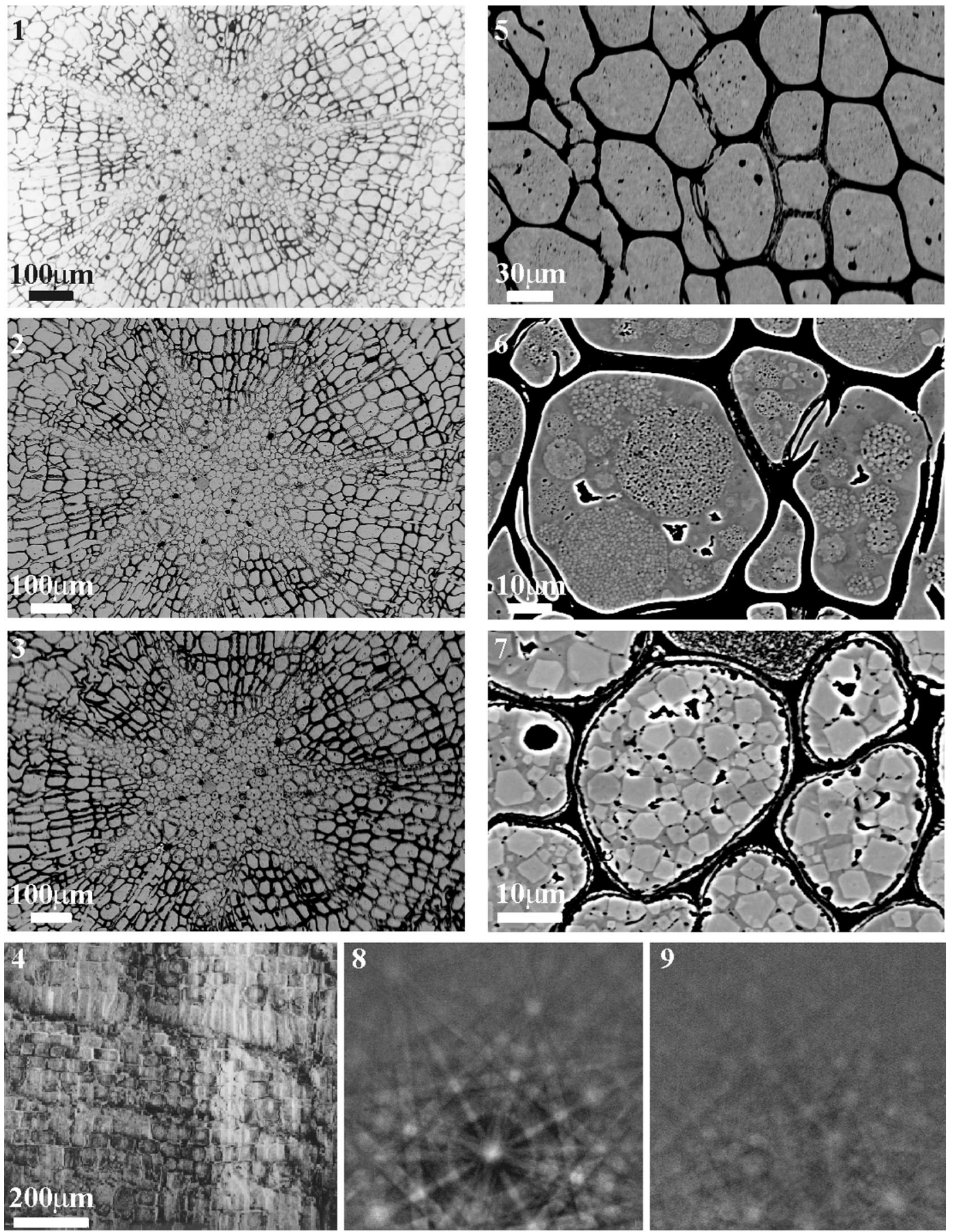
highly polished surfaces provide a large amount of optical detail concerning anatomy, which can be enhanced by chemical etching (see Kenrick, 1999 and references therein) but little information concerning the preservational state (e.g. Plate I, 1). Conversely, SEM of fracture surfaces (e.g. Plate I, 4) provides relatively little information regarding the anatomy but aids studies concerned with understanding the preservation. Traditional SEM analysis uses secondary electrons (SE) emitted from samples to provide images based on surface topography (e.g. Goldstein et al., 1992). However, the SEM is a versatile analytical instrument capable of different imaging modes using a variety of electron-specimen interactions (e.g. Lloyd, 1987). We applied these and more recent developments in SEM imaging, advanced in structural geology, based on specimen crystallography, to the understanding of our fossil specimens. This approach was combined with traditional techniques so that both anatomical and preservational information can be obtained simultaneously.

\section{SEM analysis}

Two SEM electron-specimen interactions provide images based on sample crystal structure: (1) electron channelling, which involves 'backscattered' electrons (BSE); and (2) electron backscattered diffraction (EBSD), which involves 'forescattered' electrons (FSE). BSE and FSE images are particularly useful for imaging isotropic minerals (e.g. pyrite) as they are unaffected by optical constraints that prevent the use of polarised transmitted light microscopy (i.e. optical isotropy due to cubic crystal symmetry) and chemical etching techniques (e.g. Wegner and Christie, 1983; Herwegh, 2000) that provide only qualitative crystallographic information.

Although BSE and EBSD are similar, particularly in terms of specimen preparation requirements (see below), there are significant differences in operational procedures (Fig. 1). These are discussed separately below. The SEM requirements that are common to both techniques are as follows. The instrument used in our study was a CamScan Series 4 fitted with a tungsten filament. An accelerating voltage of $20 \mathrm{kV}$ is suitable for most geological samples, including pyritised wood. Both BSE and EBSD require relatively high beam currents (e.g. 10-40 nA), that can result in a broad beam diameter and hence an overall loss of spatial resolution as magnification increases. This appears as an apparent loss of image focus (i.e. blurring

\section{PLATE I}

Comparison of optical and SEM images of pyritised wood.

1 Conventional reflected light bright field illumination image of the transverse section (T.S.) of pith region of a pyritised conifer axis.

2 Equivalent SEM/BSE image of (1)

3 Equivalent SEM/FSE image of (1) and (2).

4 Example of secondary electron (topographic) SEM image of a fractured longitudinal surface of ray cells from a pyritised angiosperm axis; note only cellular outlines are distinguished.

5 High magnification FSE image of the xylem tracheid region of the conifer axis shown in (1-3).

6 High magnification BSE image of the framboidal pyrite embedded in an ultra-fine $(<1 \mu \mathrm{m})$ pyritic cement in fibres of the conifer; note pit details are clearly recognisable (T.S.).

7 High magnification BSE image of angular pyrite embedded in an ultra-fine $(<1 \mu \mathrm{m})$ pyritic cement in the pith cells of the conifer axis (T.S.).

8 Good quality EBSD pattern from one of the angular pyrite crystallites in the pith cells. The configuration of bands is due to electron diffraction events with specific crystal lattice planes. The bright spot with dark halo (lower centre) is the crystal $\{001\}$ zone axis. Automated computer indexing systems permit exact recognition and indexing of the crystal orientations represented by these patterns, from which the simulations shown in Plate II are derived.

9 Poor quality EBSD pattern typical of those obtained from the pyrite framboids in the tracheid cells and the ultra fine pyrite cement present in both pith and tracheid cells. The image consists of several different EBSP superimposed on to each other due to the crystallite size being finer than the resolution limit of the technique. 


\section{CamScan Series 4 SEM}

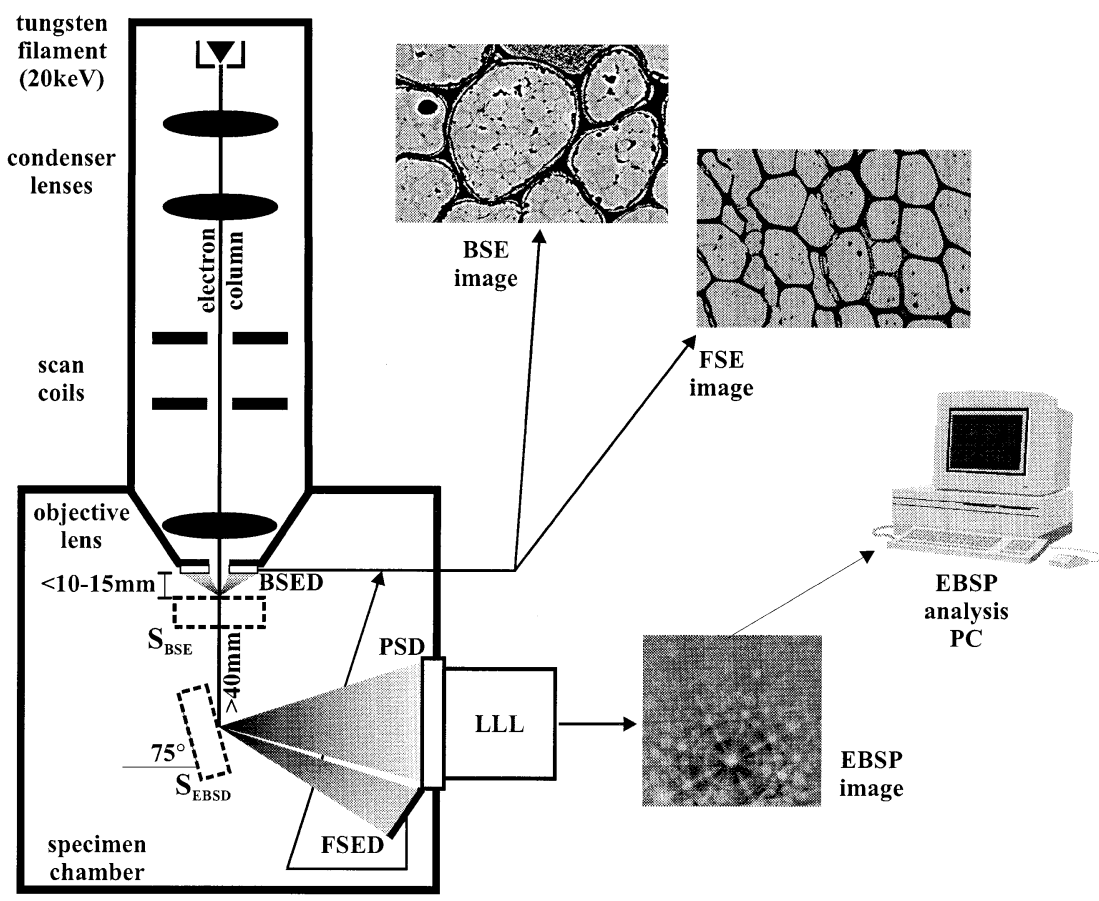

Fig. 1. Schematic SEM configuration for BSE and EBSD analyses based on a CamScan Series 4 instrument. For BSE analysis, the sample $\left(\mathrm{S}_{\mathrm{BSE}}\right)$ is horizontal, with its surface normal to the electron beam. Enhanced crystal orientation contrast is obtained by using a short $(<10-15 \mathrm{~mm})$ working distance, relative to the BSE detector (BSED) positioned on the objective lens pole piece, and a high $(10-30 \mathrm{nA})$ beam current. For EBSD analysis, the sample $\left(\mathrm{S}_{\mathrm{EBSD}}\right)$ is tilted at a high angle $\left(65-75^{\circ}\right)$ relative to the electron beam, which requires a long $(>40 \mathrm{~mm})$ working distance. Enhanced crystal orientation contrast is obtained by using a high (10-30 nA) beam current. The sample points towards both the FSE detector (FSED) and phosphor screen scintillator detector (PSD), on to which EBSP are focused. The latter is connected to a low-light-level (LLL) CCD camera. Individual EBSP are indexed, and automated EBSP analysis is performed, via a link to a dedicated computer and associated software.

of edges). Crystal boundaries orientated at low angles to the sample surface also result in apparent blurring of image detail. This is due to the depth of electron penetration into the sample. Use of field emission SEM will typically involve lower accelerating voltages (e.g. $\sim 10 \mathrm{keV}$ ) and beam currents (e.g. $<10 \mathrm{nA}$ ), resulting in better image spatial resolution.

\subsection{Electron channelling}

BSE are most commonly used to provide images based on specimen composition (e.g. Hall and Lloyd, 1983; Lloyd, 1987). However, they also contain information on crystal orientation variation due to the 'channelling' of incident electrons by the sample crystal lattice (e.g. Joy, 1974; Lloyd et al., 1981, 1991; Lloyd, 1987). Ideally, sophisticated electron optical procedures are required to produce the full range of electron channelling signals, but it is possible to obtain adequate crystal orientation-based images (e.g. Plate I, 2, 6 and 7) in most SEM using the general operating conditions described above and the following specimen configuration (Fig. 1). Specimens are positioned horizontally, normal to the electron beam. The working distance between the sample surface and the objective lens pole piece is reduced as much as possible (typically $<15 \mathrm{~mm}$; ideally $<10 \mathrm{~mm}$ ). This configuration demands a solid-state BSE detector attached to the objective lens pole piece is used (Fig. 1). 


\subsection{Electron backscattered diffraction}

EBSD is a recent, much simpler alternative to BSE crystallographic analysis (see Wilkinson and Hirsch, 1997 and Prior et al., 1999 for comprehensive reviews). It provides two complimentary images. Firstly, FSE images of the individual crystallite microstructure similar to the BSE image described above (e.g. Plate I, 3 and 5). Secondly, EBSP that are unique for a specific crystal orientation (e.g. Plate I, 8). In combination, these two images allow crystallographic orientations of individual crystallites to be identified and determined precisely. The FSE and EBSP image signals are collected using two additional electron detection systems (Fig. 1). The former is collected via simple and cheap silicon optical devices, usually wired into the conventional solid-state BSE detector circuitry. The latter requires a sophisticated and relatively expensive low light television camera and image analysis. In addition, EBSP analysis requires access to computer based pattern indexing software; we have used the Channel $+^{\circ}$ indexing system (e.g. Schmidt and Olesen, 1989). Each of these requirements is readily available for most types of SEM.

In addition to the general operating conditions described above, EBSD analysis involves the following specimen configuration (Fig. 1). Samples must be tilted to a high angle relative to the incident electron beam to achieve diffraction conditions. We have used $75^{\circ}$ in this study (see below). This results in a long working distance between the sample surface and the objective lens pole piece (typically $>40 \mathrm{~mm}$ ). The sample must also be tilted in a direction such that it faces towards the FSE and EBSD detectors.

It is possible to automate the EBSP procedure such that the electron beam is traversed across a chosen area in a step-wise manner (see example in Plate II). The EBSP produced at each point is collected, indexed and the solution written to a database. The automatic indexing procedure collects a large number of data (e.g. 180000 in this study) with a high spatial resolution (e.g. $\geq 1 \mu \mathrm{m}$ ). It is possible to turn these data into computer generated images of the microstructure, based on several different data processing parameters. Full crystal orientation images are based on the precise crystal orientation of each indexed point (e.g. Plate II, 2 and 3). They are typically colour-coded to reflect the precise crystal orientation, but here we present only their grey-scale equivalents. EBSP pattern quality band contrast (BC) or band slope (BS) images (Plate II, 4 and 5) are based on different quantifiable aspects of the EBSP signal. In both cases, increasing image contrast reflects increasing pattern quality. However, it must be emphasised that although automated SEM/EBSD analysis may prove very useful (see below), great care must be taken in processing the images, particularly where indexing success rate is poor (so-called 'zero solutions') due to specimen surface artefacts. The processing opportunities available include removal of an individual measurement point with an incorrect indexing solution relative to its neighbours ('spike correction') and 'extrapolation' of successful indexing results into adjacent 'zero solution' regions [see Lloyd (2000) for further details]. Unfortunately, such processing procedures can result in the production of false or exaggerated microstructures and/or crystal orientation components (e.g. compare the differences between Plates II, 2 and 3). See Section 3 for an example.

\subsection{Specimen preparation}

We employ a procedure established for BSE analysis of geological samples (Lloyd, 1987) whereby specimens are initially sawn into small blocks (ca. $15 \times 15 \times 5 \mathrm{~mm}$ ) and set into commercially available epoxy or polyester resins prior to polishing. The essential requirement is for a flat, smooth surface (i.e. no surface topography) which is strain free. All polishing techniques introduce some strain into the surface layers of specimens. This deformation (cold working) has a detrimental effect on EBSD images resulting in a uniform electron signal (i.e. no contrast). Fortunately polishing with progressively finer grade abrasives (e.g. alumina and diamond pastes) to 1 or $0.5 \mu \mathrm{m}$ followed by a weakly caustic colloidal silica solution (e.g. 'Syton' ${ }^{\circledR}$ ) removes all preparation damage to reveal the crystallographic microstructure (see Plate I, 2, 3, 5-9). 

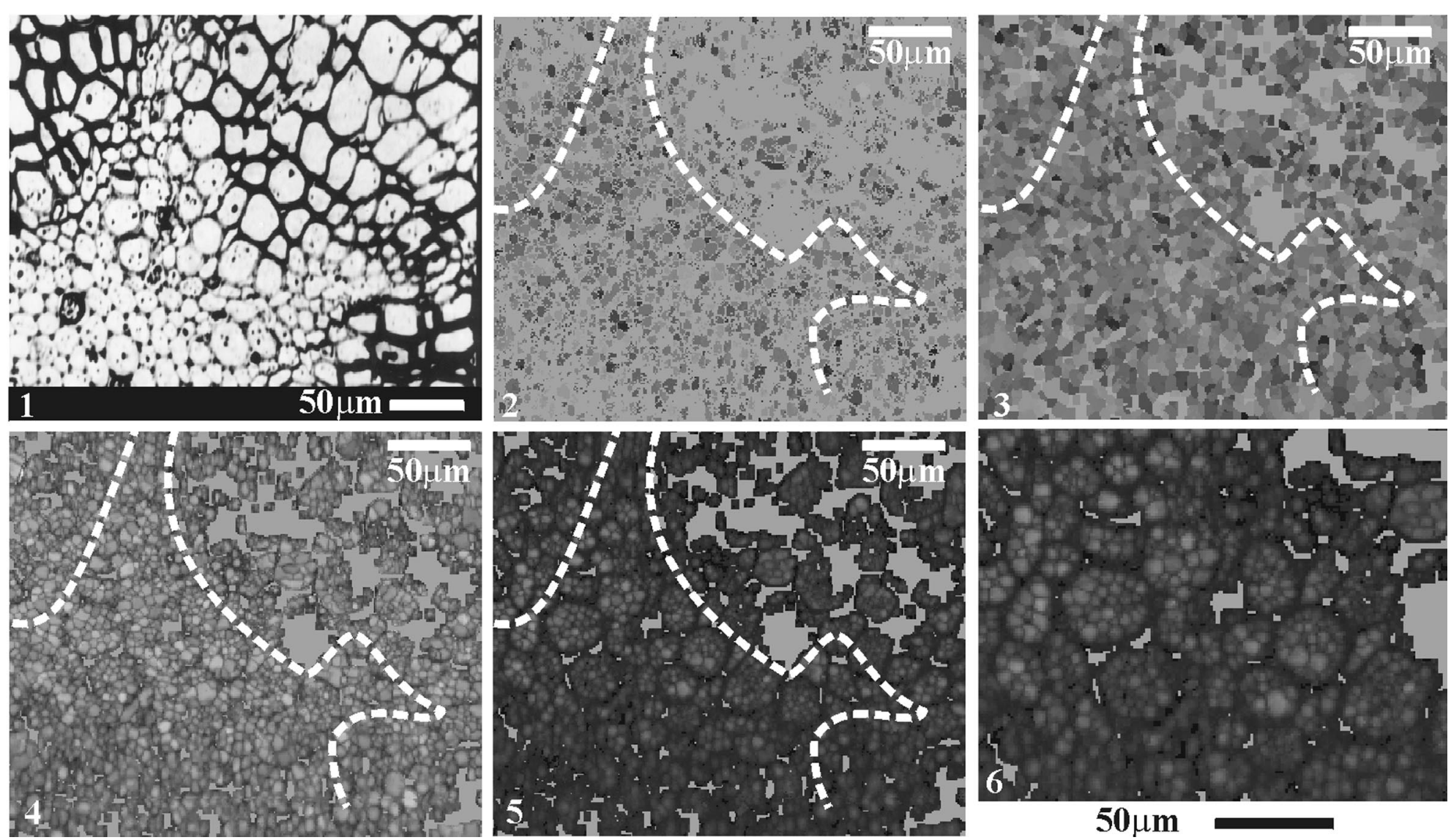

$50 \mu \mathrm{m}$

Example of automated EBSD analysis of the sample shown in Plate I, 1-3. The white line in (2-5) indicates the approximate boundary of the pith depicted in (1) Analytical details: $1 \mu \mathrm{m}$ step procedure; $350 \times$ magnification; number of points 180000 . See text for further details.

1 FSE image of area examined, showing two arcs of the pith (lower left) and tracheids.

2 Raw data image based on the full EBSP crystal orientation but without any image processing (note, these images are typically colour-coded with respect to crystal orientation, but have been reproduced here simply as the grey-scale equivalent image, with some loss of detail). Contrast variations indicate changes in crystal orientation; homogenous grey background indicates regions of zero EBSP solution.

3 Processed data image (one 'spike' and two 'extrapolation' filter passes) based on the full crystal orientation. Note increase in density of contrast variations and decrease in homogenous grey background due to processing.

4 EBSP band contrast image [based on (3)]; note now the appearance of an apparent cellular structure, incorporating angular fragments, particularly within the pith region, undetected in all previous images.

5 EBSP band slope image [based on (3)]; again note the appearance of an apparent cellular structure, incorporating angular fragments, particularly within the pith region

6 Detail of (5) showing the angular nature of the pyritisation within the original cells; note that the regions surrounding the filled cells (originally cell wall) result in relatively poor EBSP quality and hence appear dark. 
Most SEM analysis of geological material requires samples to be coated with an electrically conductive film to prevent charging. For SE imaging of topographic surfaces, gold is frequently used (Goldstein et al., 1992), whereas for BSE compositional analysis, carbon is used as this does not interfere with electron or X-ray emission signals. However, for BSE crystallographic images, the carbon layer needs to be very thin $(\sim 10 \mathrm{~nm})$ as the emission signal is restricted to $\sim 50 \mathrm{~nm}$ of the sample surface. Similar constraints apply to EBSD signals but more so as the sample is tilted to high angles (Fig. 1) and therefore presents an apparently thicker layer of carbon. However, coating is not necessarily a prerequisite for EBSD analysis where specimens are tilted in excess of $70^{\circ}$ to the incident beam (in our case $75^{\circ}$ ). In this configuration, the electron-out current density exceeds the electron-in current density (e.g. Goldstein et al., 1992) and hence charging is either significantly reduced or prevented altogether. However, specimens must be tilted into position before exposure to the electron beam or else an inherent static charge will persist. In future, use of specimen 'charge dissipation' devices (Prior, 1999, personal communication) may prevent charging artefacts altogether for tilted samples.

\section{Typical application}

We have selected a pyritised conifer axis ('twig') from the Eocene London Clay, SE England, to illustrate the potential of SEM BSE and EBSD analyses of pyritised fossil material. The SEM images (Plate I, 2 and 3 ) have been compared with conventional reflected light bright field microscopy (Plate I, 1). At relatively low magnifications the three images are similar (Plate I, 1-3). However, the SEM techniques described here provide greater opportunity to examine in detail and at higher magnifications specimen anatomy and preservation state simultaneously (e.g. Plate I, 5-7). Our investigation suggests that the technically simpler and cheaper BSE approach is often superior to the FSE image (e.g. compare Plate I, 6 and 7 with Plate I, 5). BSE analysis clearly reveals that whereas pith cells consist of angular pyrite crystal- lites in a very fine pyrite cement (Plate I, 7), tracheid cells consist of pyrite framboids in a very fine cement (Plate I, 6).

Use of EBSP provides additional evidence on the nature of the crystalline replacement of the wood by pyrite. Pith cells generally yield good quality patterns from the angular crystallites (e.g. Plate I, 8). Tracheid cells typically yield very poor quality EBSP, or no patterns at all (e.g. Plate I, 9 ). The poor quality patterns often consist of several different EBSP superimposed on to each other. This suggests a very fine crystallite size $(<1 \mu \mathrm{m})$, below the resolution limit for individual EBSP analysis. The pyrite cement in both pith and tracheid cells also yields no or superimposed EBSP, indicating a very fine pyrite crystallite size (or perhaps even an amorphous iron-sulphur material?). The superior EBSP spatial resolution offered by field emission SEM (perhaps of the order of $100 \mathrm{~nm}$ ) would considerably improve EBSP recognition of these very fine crystallites.

Finally, we have performed an automated EBSD analysis of a part of the pith-xylem boundary (Plate II, 1) at 350 times magnification using a $1 \mu \mathrm{m}$ step procedure, resulting in a total of 180000 EBSP attempted indexations (Plate II, 2). Pattern quality, and hence indexing success rate, varied considerably. They were particularly poor in the tracheid cells, as one would expect from the presence of a very fine crystallite size in both the framboidal and cement pyrite. The crystal microstructure of such regions could not be 'recovered' even by careful image processing of the raw data image (Plate II, 3). Similarly, pith cell cement and the walls to both pith and tracheid cells also provided poor or zero EBSP solutions, the latter clearly due to the poor pyrite replacement (e.g. see Plate I). Although the pith cells returned a significantly higher density of successful indexations, the microstructural detail present in these cells was missing from the 'full crystal orientation' representations (Plate II, 2 and 3) due to the random nature of the pyrite crystallite orientations. Thus, only individual pyrite crystallites are recognised rather than the cell structure. This suggests that pyritisation does not involve selection of preferred crystal orientations by the plant microstructure. However, use of EBSP band and slope contrast 
information provides additional and perhaps unique insights into both the anatomy of the wood and the pyrite preservation process(es). Both types of image (Plate II, 4-6) clearly recognised the infill of all pith cells by well-crystallised angular pyrite. Some tracheid cells were also replaced/preserved in this manner, but many failed to yield recognisable EBSP and therefore potentially reflect a different preservation mode, which might be related to a difference in original anatomical state(?). We intend to pursue this investigation of the anatomy and preservation of these and other pyritised fossil wood samples using the novel SEM techniques described in this contribution.

\section{Acknowledgements}

The authors thank Eric Condliffe for encouraging them to pursue this work. GEL acknowledges N.E.R.C. Grant GR9/3223 for provision of the automated EBSD system. The authors thank Dr. T. Jones for his suggestions for improving this manuscript.

\section{References}

Barghoorn, E.S., Nichols, R.L., 1961. Sulphate-reducing bacteria and pyritic sediments in Antarctica. Science 134, 190.

Berner, R.A., 1984. Sediment pyrite formation: an update. Geochim. Cosmochim. Acta 48, 605-615.

Berner, R.A., 1985. Sulphate reduction, organic matter decomposition and pyrite formation. Philos. Trans. R. Soc. London A 315, 25-38.

Briggs, D.E.G., Bottrell, S.H., Raiswell, R., 1991. Pyritization of soft-bodied fossils: Beecher's Trilobite Bed Upper Ordovician, New York State. Geology 19, 1221-1224.

Briggs, D.E.G., Raiswell, R., Bottrell, S.H., Hatfield, D., Bartels, C., 1996. Controls on the pyritization of exceptionally preserved fossils: an analysis of the Lower Devonian Hunsruck Slate of Germany. Am. J. Sci. 296, 633-663.

Canfield, D.E., Raiswell, R., 1991. Pyrite formation and fossil preservation. In: Allison, P.A., Briggs, D.A. (Eds.), Taphonomy: Releasing the Data Locked in the Fossil Record, Topics in Geobiology Vol. 9. Plenum Press, New York, pp. 337-387.

Drobner, E., Huber, H., Wachtershäuser, G., Rose, D., Stetter, K.O., 1990. Pyrite formation linked with hydrogen evolution under anaerobic conditions. Nature 346, 742-744.

Goldstein, J.I., Newbury, D.E., Echlin, P., Joy, D.C., Romig, A.D., Lyman Jr., C.E., Fiori, C., Lifshin, E., 1992. Scanning
Electron Microscopy and X-ray Microanalysis, 2nd ed. Plenum Press, New York.

Hall, M.G., Lloyd, G.E., 1983. The SEM examination of geological samples with a semiconductor backscattered electron detector: reply. Am. Min. 68, 843-845.

Herwegh, M., 2000. A new technique to automatically quantify microstructures of fine grained carbonate mylonites twostep etching combined with SEM imaging and image analysis. J. Struct. Geol. 22, 391-400.

Hudson, J.D., 1982. Pyrite in ammonite-bearing shales from the Jurassic of England and Germany. Sedimentology 29, 639-667.

Joy, D.C., 1974. Electron channelling patterns in the SEM. In: Holt, D.B., Muir, M.D., Boswarva, I.M., Grant, P.R. (Eds.), Quantitative Scanning Electron Microscopy. Academic Press, New York, pp. 131-182.

Kenrick, P., 1999. Opaque petrifaction techniques. In: Jones, T.P., Rowe, N.P. (Eds.), Fossil Plants and Spores: Modern Techniques. Geological Society, London, pp. 87-91.

Kenrick, P., Edwards, D., 1988. The anatomy of Lower Devonian Gosslingia breconensis Heard based on pyritized axes, with some comments on the permineralization process. Bot. J. Linn. Soc. 97, 95-123.

Lloyd, G.E., 1987. Atomic number and crystallographic contrast images with the SEM: a review of backscattered electron techniques. Miner. Mag. 51, 3-19.

Lloyd, G.E., 2000. Grain boundary contact effects during faulting of quartzite: an SEM/EBSD analysis. J. Struct. Geol. (in press).

Lloyd, G.E., Hall, M.G., Cockayne, B., Jones, D., 1981. Application of scanning electron microscopy to the study of deformed rocks. Tectonophysics 78, 687-698.

Lloyd, G.E., Schmidt, N.-H., Mainprice, D., Prior, D.J., 1991. Crystallographic textures. Miner. Mag. 55, 331-345.

Poole, I., 1993. A dipterocarpaceous twig from the Eocene London Clay Formation of Southeast England. Palaeontology 49, 155-163.

Poole, I., 1996. Conifer twigs from the London Clay (Eocene) of Southeast England. Rev. Palaeobot. Palynol. 94, 25-37.

Poole, I., Wilkinson, H.P., 1992. Two sapindaceous woods from the London Clay (Eocene) of Southeast England. Rev. Palaeobot. Palynol. 75, 65-75.

Poole, I., Wilkinson, H.P., 1999. A celastraceous twig from the London Clay (Eocene) of Southeast England. Bot. J. Linn. Soc. $129,165-176$.

Prior, D.J., Boyle, A.P., Brenker, F., Cheadle, M.C., Day, A., Lopez, G., Potts, G.J., Reddy, S., Spiess, R., Timms, N., Trimby, P., Wheeler, J., Zetterstrom, L., 1999. The application of electron backscatter diffraction and orientation contrast imaging in the SEM to textural problems in rocks. Am. Mineral. 84 (in press).

Raiswell, R., 1997. A geochemical framework for the application of stable sulphur isotopes to fossil pyritization. J. Geol. Soc. London 154, 343-356.

Raiswell, R., Whaler, K., Dean, S., Coleman, M.L., Briggs, D.E.G., 1993. A simple 3-dimensional model of diffusion with precipitation applied to localized pyrite formation in 
framboids, fossils and detrital iron minerals. Mar. Geol. 113, 89-100.

Rickard, D., 1997. Kinetics of pyrite formation by the $\mathrm{H}_{2} \mathrm{~S}$ oxidation of iron (II) monosulfide in aqueous solutions between $25^{\circ} \mathrm{C}$ and $125^{\circ} \mathrm{C}$ : the rate equation. Geochim. Cosmochim. Acta 61, 115-134.

Rickard, D., Luther, G.W., 1997. Kinetics of pyrite formation by the $\mathrm{H}_{2} \mathrm{~S}$ oxidation of iron (II) monosulfide in aqueous solutions between $25^{\circ} \mathrm{C}$ and $125^{\circ} \mathrm{C}$ : the mechanism. Geochim. Cosmochim. Acta 61, 135-147.

Rixon, A.E., 1976. Fossil Animal Remains: their Preparation and Conservation. Athlone Press, London.

Schmidt, N.H., Olesen, N.O., 1989. Computer aided determination of crystal lattice orientation from electron channelling patterns. Can. Min. 27, 15-22.
Stürmer, W., Bergström, J., 1973. New discoveries on trilobites by X-rays. Paläontol. Z. 47, 104-141.

Wegner, M.W., Christie, J.M., 1983. Chemical etching of deformation sub-structures in quartz. Phys. Chem. Mins. 9, $67-78$.

Wilkinson, A.J., Hirsch, P.B., 1997. Electron diffraction based techniques in scanning electron microscopy of bulk materials. Micron 28, 279-308.

Wilkinson, H.P., 1981. The anatomy of the hypocotyls of Ceriops Arnott (Rhizophoraceae), Recent and fossil. Bot. J. Linn. Soc. 82, 139-164.

Wilkinson, H.P., 1984. Pyritised twigs from Sheppey. Tertiary Res. 5, 189-198.

Wilkinson, H.P., 1988. Sapindaceous pyritised twigs from the Eocene of Sheppey, England. Tertiary Res. 9, 81-86. 